\title{
A Study on the Manufacturing of Molybdenum Pins for Electrodes
}

\section{Jeong-Ick Lee}

(Professor, Dept. of Mechanical Design, Inha Technical College, 100 Inha-ro, Nam-gu, Incheon, 22212, Korea, +82-32-870-2503 and jilee@inhatc.ac.kr)

Article History:Received:11 november 2020; Accepted: 27 December 2020; Published online: 05 April 2021 Abstract : The molybdenum cup and molybdenum pin, which are the main materials of the molybdenum electrode used for
the LCD BLU CCFL electrode, have not been developed in Korea and imported from Japan. In this paper, especially,
research on prototype manufacturing and CAE analysis is performed to develop a molybdenum pin. In this research, to
develop the manufacturing technology of molybdenum pin used for CCFL electrode of LCD BLU, development of linear
processing technology, development of molybdenum wire surface treatment technology, development of wire cutting
technology, production of molybdenum pin, design and fabrication of JIG and Fixture for inspection, molybdenum pin
prototyping and analysis, and development of $100 \%$ molybdenum pin inspection technology. The development of
molybdenum pins developed through this research can overcome Japan's technological level, which depends entirely on
imports from Japan, and it is thought that the development will have a significant impact on the overall industry using
molybdenum pins.

Keywords: Molybdenum pin, LCD, BLU, Prototype manufacturing, CAE analysis.

\section{Introduction}

Backlights are used as materials for a variety of home appliances and light sources, and are broadly divided into LED, CCFK and EEFL. Among them, CCFL can be said to be the most versatile backlight. Compared to the EEFL, CCFL has a simpler production process and outperforms LED in terms of price. It is also widely used not only in home appliances but also in fields such as electronic bulletin boards. [1, 2] Liquid Crystal Display (LCD), a type of thin display, has advantages in terms of power consumption and mobility, and will continue to drive growth centered on general-purpose displays. Figure1 is the BLU structure used for TV. [3-5] CCFL, which serves as a light source for LCDs, is similar to general fluorescent lamps, but has the advantage of being small in size, high in brightness, and long service life. [6, 7] CCFL and electrode rod structures are manufactured by welding Durmet to Kovar pins as shown in figure 2 and laser welding or resistance welding to Ni cups where glass is beaded. A nickel electrode composed of Kovar pins and Ni cups is changed to molybdenum electrodes (combination of molybdenum cups and molybdenum pins) according to CCFL brightness and life requirements. [8-10] The molybdenum cup and pins, which are the materials for molybdenum electrodes, are not processed in Japan and are imported from Japan in all quantities.

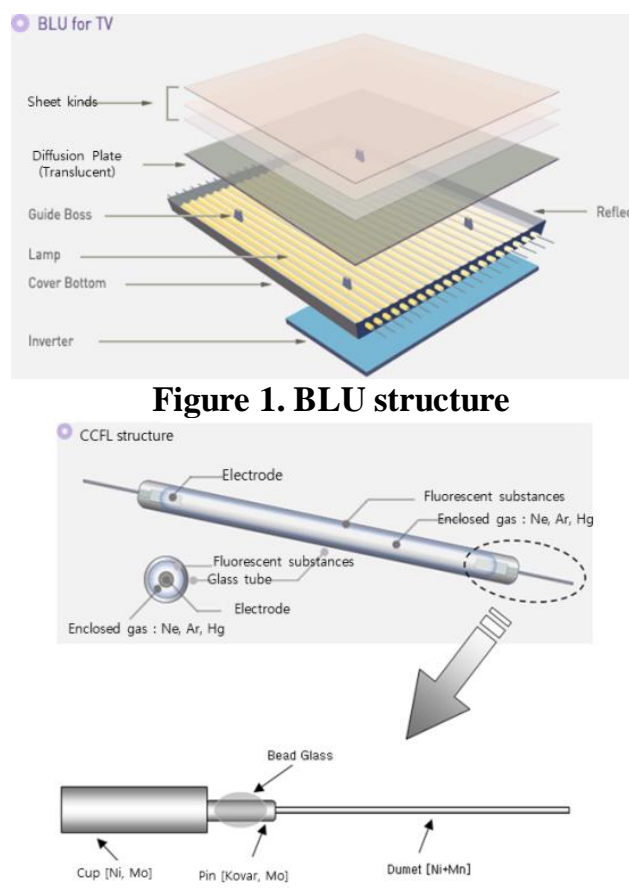

Figure 2. CCFL and electrode structure

*Corresponding author: Jeong-Ick Lee

Professor, Dept. of Mechanical Design, Inha Technical College, 100 Inha-ro, Nam-gu, Incheon, 22212, Korea, jilee@inhatc.ac.kr 
In this task, we studied the manufacturing process of molybdenum pins for LCD and conducted research on the development of linear processing technology, molybdenum wire surface treatment technology, wire cutting technology, design and manufacture of JIG and Fixture for manufacturing and inspection of molybdenum pins, prototype and analysis of molybdenum pins, and development of full number inspection technology of molybdenum pins. [11, 12]

\section{CCFL Technology Development and Details}

A molybdenum pin is made of a molybdenum wire having a diameter of $1.0 \mathrm{~mm}$ or more. Molybdenum pinning processing goes through the following steps. It consists of straightening technology, cutting technology, surface treatment technology, and finally total inspection technology. In this study, the ultimate goal is to develop an automated process that enables the production and inspection of molybdenum pins.

During the manufacturing process, minor changes in the external environment can cause defects such as cracks in materials, which can cause serious failures in the performance of CCFL products and therefore require quality assurance and full-scale inspection. Figure 3 is a magnified view of fine cracks on molybdenum pins, and figure 4 shows the occurrence of defective leaks on fine cracks.

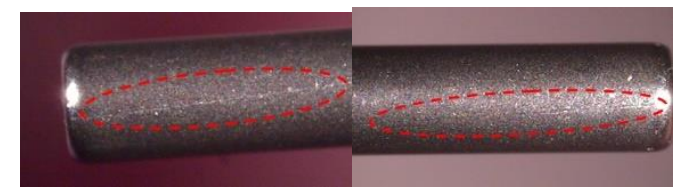

Figure 3. Small crack magnification of molybdenum pin
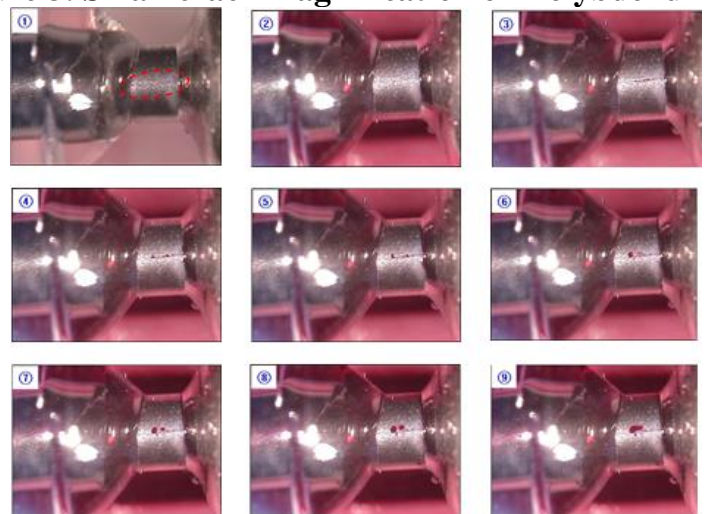

Figure 4. Bad leak occurrence of small crack (Penetrant experiment)

For the ultimate development goals of this research, technology development is necessary according to the following procedures. The first linear treatment technology determines equipment design for a linear machine of a high-speed rotating method, linear machine optimum machining conditions for optimum linear molding, linear treatment technology development for molybdenum wire including centerless grinding processing, the second molybdenum wire surface treatment technology development includes removal of foreign substances such as graphite used when drawing molybdenum wire, conditions and technology development for surface friction processing for surface treatment, the third involves development of bundling technology for minimizing material deformation, and linear design of molybdenum wire for manufacturing and inspection. Fifth is the prototype and analysis of molybdenum fins, the thermal transfer analysis of molybdenum fins, and the threedimensional precision measurement of molybdenum fins. Finally, the development of the whole inspection technology of molybdenum fins means the development of the whole inspection technology of molybdenum fins and the development of equipment.

2. Experimental Manufacturing at molybdenum pin, 3D precision measurement and CAE analysis 2.1. Molybdenum pin manufacturing

Among the various molybdenum pin standards, a production schedule standard was made and shown in figure 5 below. 


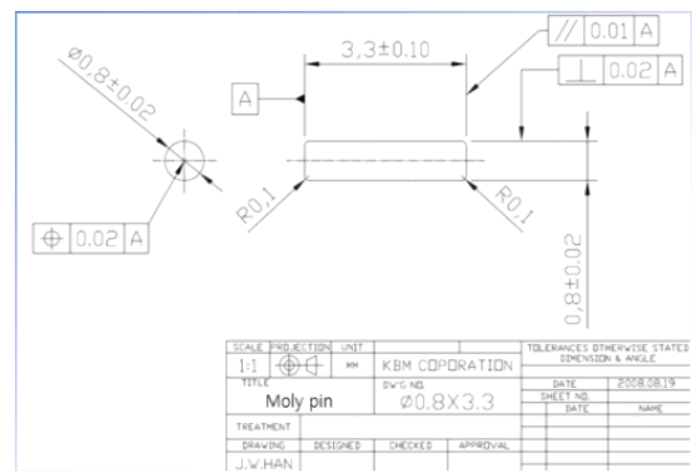

Figure 5. Prototype drawing of molybdenum pin

\subsection{Molybdenum pin prototype speculation}

The standards for molybdenum pin prototypes shall be within the dimensional tolerance range of parts A, B, and $\mathrm{C}$, and the surface gloss and surface illuminance shall be equal to or greater than those of products currently in use. In contrast, the standards for A, B, and C and the prototype standards for tolerance are shown in figure 6 .

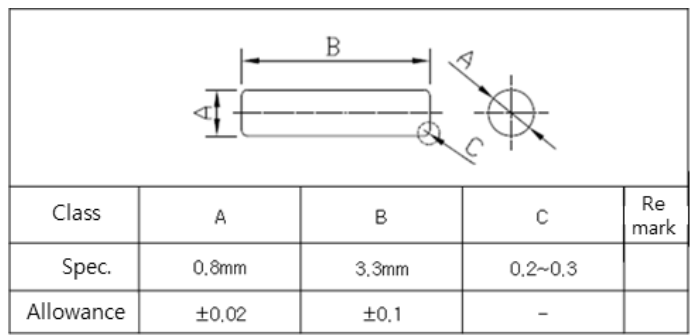

Figure 6. Specification of prototype

\subsection{Molybdenum pin prototype inspection report}

The results of the first prototype were found to be improved, and after additional improvement work, the second prototype was produced. The report of the prototype is shown in figure 7.
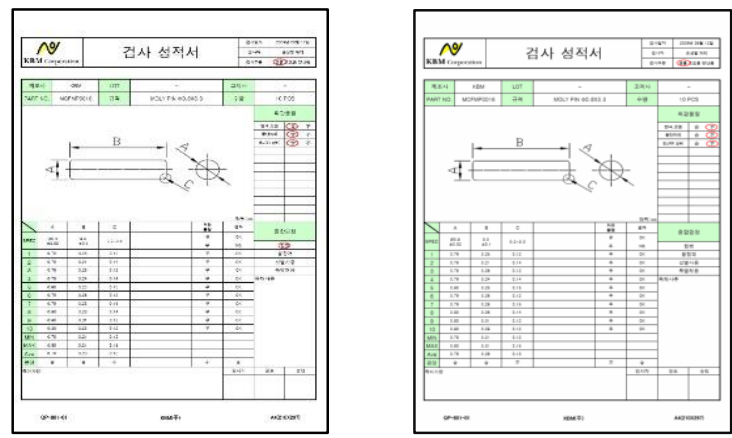

Figure 7. Prototype certification of the first time and the second time

\subsection{Molybdenum pin 3D precision measurement}

There are three methods of molybdenum pin 3D precision measurement: 3D-CT imaging of the first prototype, laser confocal microscopy, and X-Ray imaging. First, 3D-CT photography is to confirm the epicenter of molybdenum pins after centerless processing, and the epicenter measurement of the prototype is shown in figure 8 .

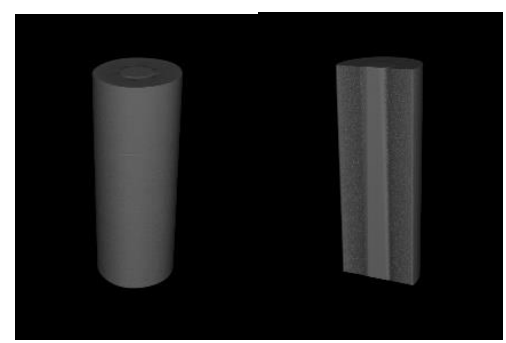




\section{Figure 8. Prototype roundness measurement [3D-CT]}

For precision impression of laser confocal microscope (metal microscope), the depth value of Crack was measured by scanning the shape of $\mathrm{Z}$ axis in the depth direction with Laser and realizing the image taken by tomography in 3D.(Minimum unit: $0.001 \mu \mathrm{m}$ ) The test crack depth measurement of a metal microscope is shown in figure 9.

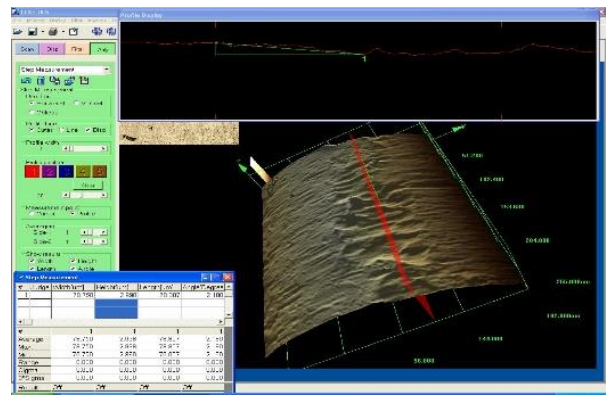

Figure 9. Prototype crack depth measurement (metal microscope)

Finally, for the X-ray photography, X-ray photography was performed for the purpose of microcrack inspection inside molybdenum wire, and the presence or absence of Crack was determined and shown in figure 10.

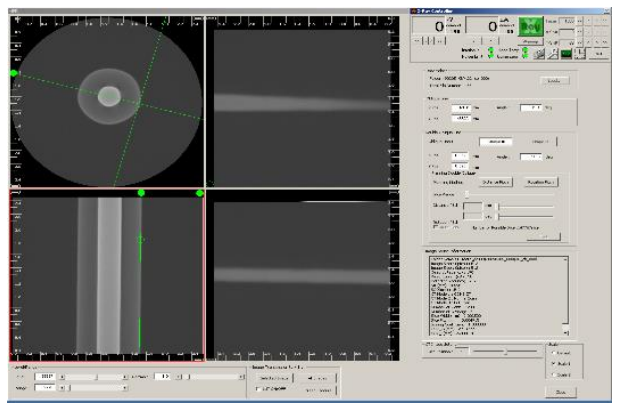

Figure 10. X-Ray shooting for prototype

\subsection{The first and the second time comparisons for prototype}

The first and second production of the prototype are shown in Table 1.

Table 1: The first and the second time comparisons for prototype

\begin{tabular}{|c|c|c|c|}
\hline Classification & $\begin{array}{c}\text { Production } \\
\text { quantity }\end{array}$ & $\begin{array}{c}\text { Production } \\
\text { period }\end{array}$ & Acceptance rate \\
\hline $\begin{array}{c}\text { Prototype } \\
\text { the first }\end{array}$ & $\begin{array}{c}190,000 \\
\text { PCS }\end{array}$ & $84 \mathrm{hr}$ & $52 \%$ \\
\hline $\begin{array}{c}\text { Prototype } \\
\text { the second }\end{array}$ & $\begin{array}{c}390,000 \\
\text { PCS }\end{array}$ & $62 \mathrm{hr}$ & $78 \%$ \\
\hline
\end{tabular}

Comparing these dimensions, the total length, outer diameter, and corner rounding $(\mathrm{R})$ dimensions are different. For comparison of electrical dimensions, the standard tolerance was evaluated on the basis of $3.30 \pm 0.1 \mathrm{~mm}$. Both $\mathrm{Cp}$ and $\mathrm{CpK}$ are insufficient due to the large variation and the average deviation of the primary prototype to the lower limit $(3.20 \mathrm{~mm})$ of the standard, and some of the products are out of the lower limit of the standard. The secondary prototype was manufactured to be distributed to the standard size $(3.30 \mathrm{~mm})$ by improving the cutter, and both $\mathrm{Cp}$ and $\mathrm{CpK}$ are good, and the comparison of the prototype's total length histogram and distribution diagram is figure. It seems to be figure 11. 


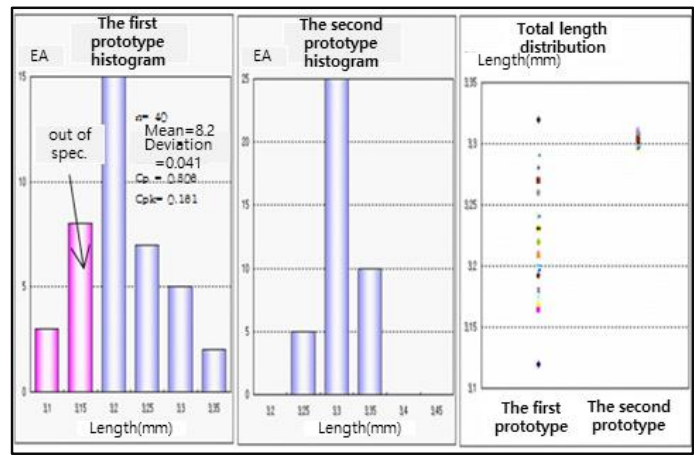

Figure 11. Comparison of prototype total length histogram and distribution

In the outer diameter dimension comparison, the standard tolerance is evaluated on the basis of $\phi 0.80 \pm 0.02 \mathrm{~mm}$. Although the first prototype is located on average at a slightly lower limit, the variation in the total length of the prototype is small, and both $\mathrm{Cp}$ and $\mathrm{CpK}$ are of a normal level. The secondary prototype is located at a slightly upper limit and close to the standard $\phi 0.80$. Comparison of the outer diameter histogram and distribution map of the prototype is figure 12 .

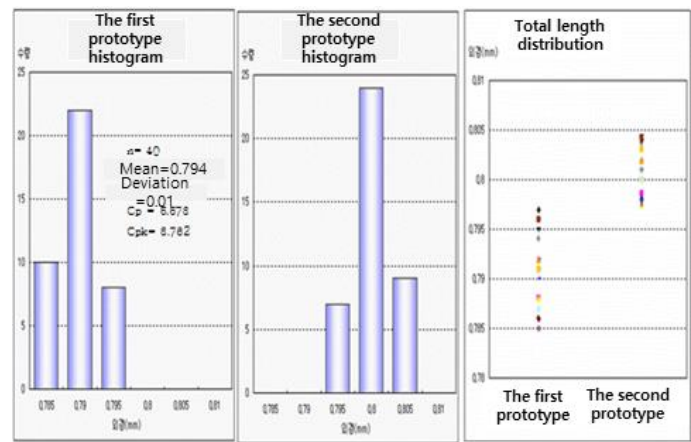

Figure 12. Comparison of the outer diameter histogram and distribution map of the prototype Corner rounding $(\mathrm{R})$ dimension comparison is as follows: The standard tolerance shall be evaluated on the basis of $0.2-0.3 \mathrm{~mm}$. The size of the first prototype was about 0.13 millimeters, and it became the shape of the epicenter. The second prototype was made in an elliptical corner round shape similar to the current product for sale, and the size was maintained to be more than $0.2 \mathrm{~mm}$. The projector comparison measurement for corner rounding $(\mathrm{R})$ dimension comparison is figure 13 .
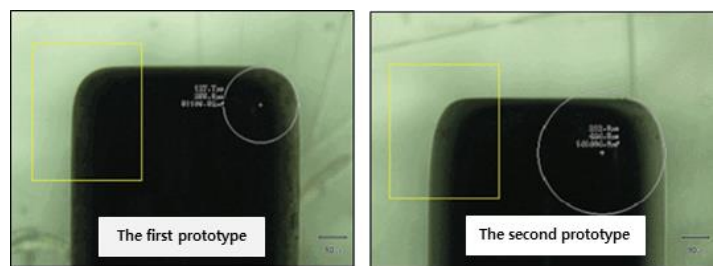

Figure 13. Projector comparison measurements

There is a comparison of appearance by optical microscope and SEM. A comparison of appearance by optical microscope shows that the primary prototype does not have a flat cut surface and includes oblique products. As a result, it was not possible to completely remove the scratch on the cross section that occurred during cutting. The second prototype was made flat by improving the conditions of precision cutters. Figure14 is a comparison of optical microscopes of the first and the second prototypes.

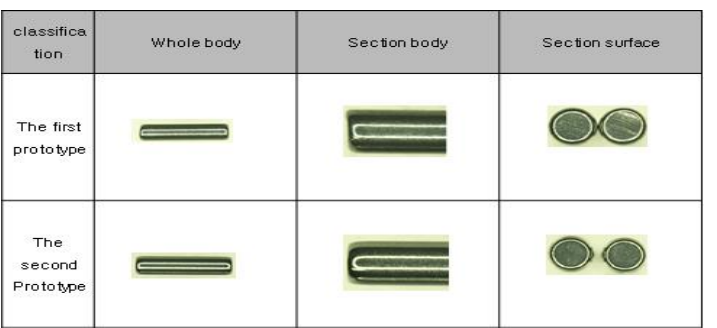

Figure 14. Comparison shoot of optical microscope 
In the comparison of appearance by SEM comparison, residual foreign substances are attached to the primary prototype after the surface treatment. Although no extreme difference is seen in the comparison of the secondary reflection electron commercial surface unevenness, it can be confirmed that surface scratch remains on the cut surface in the comparison of the cross section. In the secondary prototype, the remaining foreign substances were removed by ultrasonic cleaning, and the surface scratch of the cut surface was removed by changing the conditions of the precision cutter. The comparative photography of the first and second prototype by SEM is Fig. It is shown in figure 15.

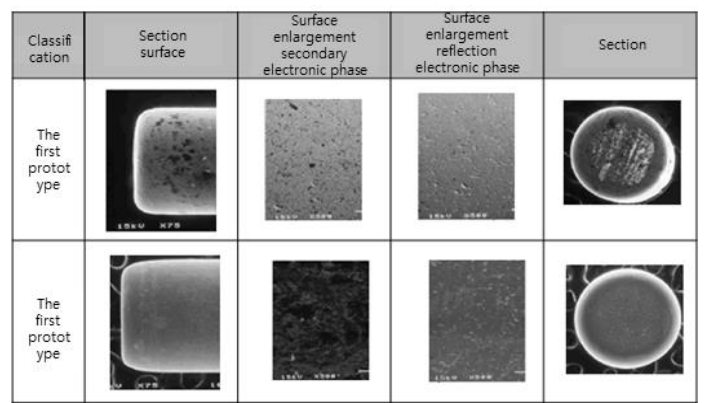

Figure 15. Comparison shooting of SEM

The second prototype was applied to complement the problems arising from the first prototype, and the improvements made by this study were as follows: Firstly, in the case of the number of electrical devices, the hexagon is maintained constant by changing from the Hand Swaging multiple flux system to the Press Swaging system, and no change in wire straightness occurs, and no distortion occurs in precision cutting, thereby reducing the deviation of the length. A micrometer header is additionally mounted on the precision cutter so that the micrometer header can be finely adjusted up to $0.01 \mathrm{~mm}$. In the case of the outer diameter dimension, the RPM value and working time of the high speed barrel polishing machine are corrected. The RPM of the first prototype was increased by about $10 \%$, and the working time was reduced by about 5\%.(125 RPM, 17 hours) Third, in the case of appearance, vinyl containers were stored after drying after high-speed barrels and after natural drying. However, when the second prototype was manufactured, the containers were washed with ultrasonic waves and dried with an electric dryer in order to remove foreign substances. The containers were sealed and stored in storage. In addition, the scratch of the surface cross section is improved by changing the conditions of the high-speed burrel polishing machine and the precision cutting machine, respectively.

\subsection{Molybdenum pin heat transfer analysis}

In analyzing CCFL with ANSYS, if conditions are given according to the material properties first, it is found through analysis that the temperature of the cup made of nickel or molybdenum is the highest if the temperature of the cup part is shown to be close to $500^{\circ} \mathrm{C}$ at room temperature, the temperature is slightly lowered by pins, and the temperature of the Dumet part made of the synthesis of nickel and manganese is lowered as it moves away from the cup. The CCFL heat transfer analysis for these is as follows.
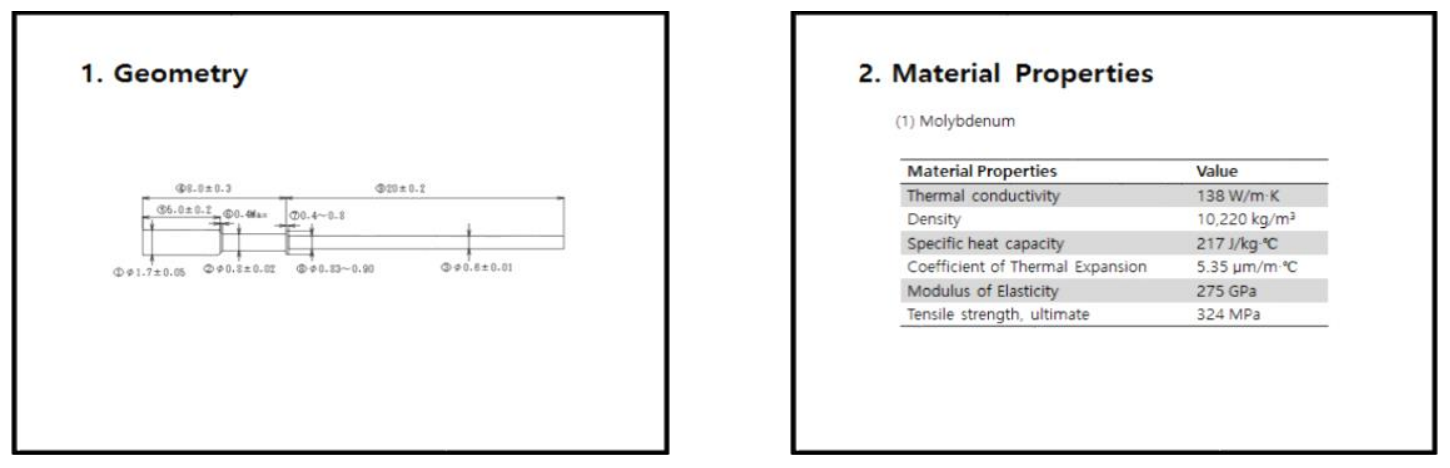

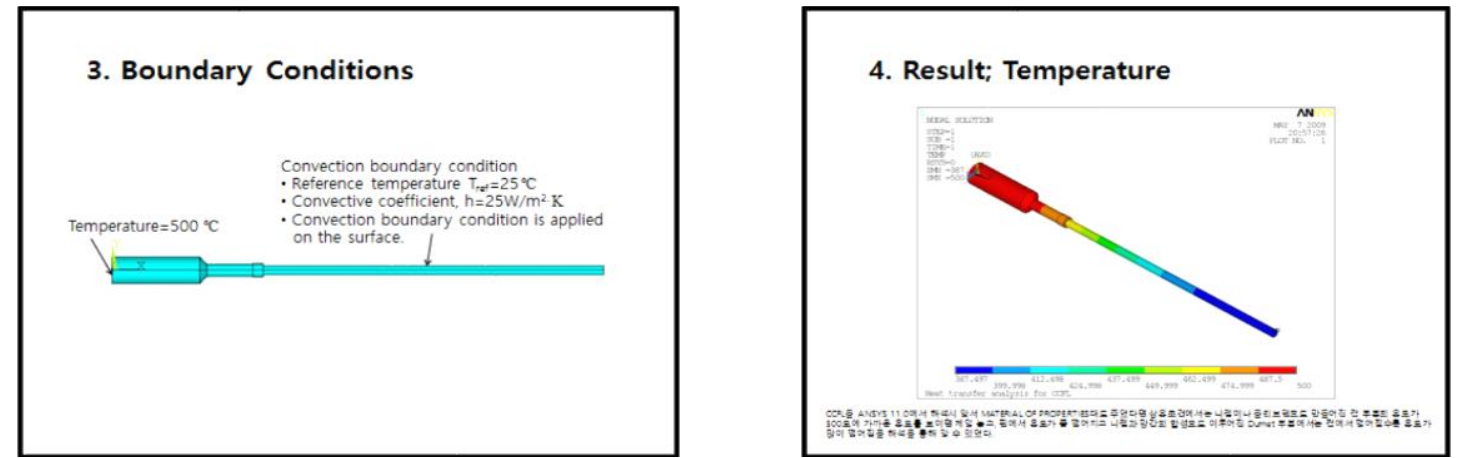

\section{Conclusions}

Because molybdenum pins are manufactured on CCFL electrodes of LCD backlight, precise processing and inspection are difficult due to material problems, so research on uniform production is needed. In this study, a molybdenum pin was prototype, and after 3D precision measurement of the molybdenum pin, heat transfer analysis was performed at the end to prove its validity. First of all, after the first trial, additional improvement work was carried out to develop a prototype satisfying the standards. Secondly, molybdenum pin 3D precision measurement methods were used to measure the depth of cracks in the prototype and to experiment with microcracks using a metal microscope among 3D-CT photography, laser control microscopy, and X-Ray photography. Through the production of the first and second prototypes, a comparison of full length dimensions, a comparison of outer diameter dimensions, and a comparison of corner-rounding dimensions were also conducted, and the distribution chart of the full length was shown in histograms. Corner Rounding compared SEM with an optical microscope and proved that the secondary prototype was highly complete. Thirdly, CCFL conducted CAE analysis through ANSYS and confirmed that when cup parts made of nickel or molybdenum show temperatures close to $500^{\circ} \mathrm{C}$ to $\mathrm{DP}$ at room temperature, the temperature drops slightly at the pin, and in Dumet parts made of nickel and manganese synthesis, the temperature drops further away from the cup. The research is part of the production stage of molybdenum pins.

\section{Acknowledgements}

This work was supported by INHA TECHNICAL COLLEGE Research Grant.

\section{References}

1. Zaitsu, T., Inoue, I., Ohnishi, O. and Iwanoto, A., (1992) 2MHz Power Converter with Piezoelectric Ceramic Transformmer. IEEE INTELEC'92 Proc. 430-437.

2. Zaitsu, T., Shigehisa, T. and Shoyama, M., (1996) Piezoelectric Transformaer Converter with PWM Control. IEEE APEC'96 Proc. 279-283.

3. Sun, N. and Hesterman, H. B. (1997) Pspice Frequency Dynamic Fluorscent Lamp Model. IEEE APEC Conference Record, 641-647.

4. Zaitsu, T., Inoue, T., Ohnishi, O. and Sasaki, Y., (1997) 2MHz Power Converter with Piezoelectric Ceramic Transformer. IEICE Transactions on Electronics, E77-C(2).

5. Hwang, L. H., Yoo, J. H., Kim, J. R., Jang, E. S., Lee, C. S., Cho, M. T. and Kim, J. S., (2002) A study on the T5 Fluorescent Lamp Ballast used Contour Vibration Mode Piezoelectric Transformer using a OneChip Micro-controller : ISAF. 287-290.

6. Hwang, L. H., Yoo, J. H., Kim, J. R., Jang, E. S., Oh, D. G., Jeong, Y. H., Ahn, K. S. and Cho, M. T., (2004) Fabrication and characteristics of PDA LCD backlight driving circuit using piezoelectric transformer, Sensor and Actuator, 74-78.

7. Hwang, L. H., Yoo, J. H., Kim, J. R., Jang, J. H., Cho, M. T., Ahn, I. S. and Song, H. B., (2005) A study on Driving of $35 \mathrm{~W}(\mathrm{~T} 5)$ fluorescent lamp byy the electric ballast using piezoelectric transformer, ICCE, psi-60.

8. Kim, Y. C., (2006) Modeling of Piezoelectric Transformer and CCFL by PSPICE Circuit Analysis. Journal of the Korea Academy-industrial cooperation Society, 7(3), 350-357.

9. Lee, J. I., Lee, E. S. and Yoo, B. I., (2008) CCFL by PSPIECE Circuit Analysis, Journal of the Korea Academyy-industrial cooperation Society, 7(3), 350-357.

10. Lee, J. I., (2009) The Development of CCFL Electrode Nickle Cup of High Brightness and High Life. Proceedings of Korean Society of Mechanical Technology, 43-47.

11. Moon, C. B., Jung, U. K., Lee, H. S., Lee, J. Y., Lee, H. Y., Kim, B. M. and Yang, H. S., (2010) CCFL Defects Detection Algorithm with Shooting Environment. Proceedings of the Korea Information Processing Society Conference, 365-368. 
12. Moon, C. B., Ahn, Y. H., Lee, H. Y., Kim, B. M. and Oh, D. W., (2010) Implementation of Automatic Detection System for CCFL's Detection based on Combined Lighting, Journal of the Korea industry information Systems Research, 69-81. 